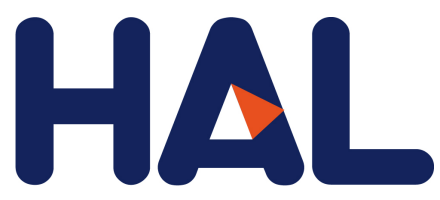

archives-ouvertes

\title{
Changes in risky sexual behaviours among West African MSM enrolled in a quarterly HIV testing and counselling prevention programme (CohMSM ANRS 12324 - Expertise France).
}

Pierre-Julien Coulaud, Luis Sagaon-Teyssier, Mohamed Mimi, Gwenaelle Maradan, Marion Mora, Michel Bourrelly, Bintou Dembélé Keita, Abdoul Aziz Keita, Camille Anoma, Stéphane-Alain Babo Yoro, et al.

\section{To cite this version:}

Pierre-Julien Coulaud, Luis Sagaon-Teyssier, Mohamed Mimi, Gwenaelle Maradan, Marion Mora, et al.. Changes in risky sexual behaviours among West African MSM enrolled in a quarterly HIV testing and counselling prevention programme (CohMSM ANRS 12324 - Expertise France).. Sexually Transmitted Infections, BMJ Publishing Group, 2020, 96 (2), pp.115-120. 10.1136/sextrans-2018053892 . hal-02511753

\section{HAL Id: hal-02511753 \\ https://hal.archives-ouvertes.fr/hal-02511753}

Submitted on 18 May 2021

HAL is a multi-disciplinary open access archive for the deposit and dissemination of scientific research documents, whether they are published or not. The documents may come from teaching and research institutions in France or abroad, or from public or private research centers.
L'archive ouverte pluridisciplinaire HAL, est destinée au dépôt et à la diffusion de documents scientifiques de niveau recherche, publiés ou non, émanant des établissements d'enseignement et de recherche français ou étrangers, des laboratoires publics ou privés. 


\title{
Changes in risky sexual behaviours among West African MSM enrolled in a quarterly HIV testing and counselling prevention programme (CohMSM ANRS 12324 - Expertise France)
}

\author{
Pierre-Julien Coulaud, ${ }^{\oplus 1,2}$ Luis Sagaon-Teyssier, ${ }^{1,2}$ Mohamed Mimi, ${ }^{1,2}$ \\ Gwenaëlle Maradan, 1,2 Marion Mora, ${ }^{1,2}$ Michel Bourrelly, ${ }^{1,2}$ Bintou Dembélé Keita, ${ }^{3}$ \\ Abdoul Aziz Keita, ${ }^{3}$ Camille Anoma, ${ }^{4}$ Stéphane-Alain Babo Yoro, ${ }^{4}$ Elias Ter Tiero Dah, ${ }^{5,6}$ \\ Christian Coulibaly, ${ }^{7}$ Ephrem Mensah, ${ }^{8}$ Selom Agbomadji, ${ }^{8}$ Pamela Palvadeau, ${ }^{9}$ \\ Adeline Bernier, ${ }^{9}$ Daniela Rojas Castro, ${ }^{1,9}$ Clotilde Couderc, ${ }^{10}$ Christian Laurent, $^{10}$ \\ Bruno Spire, ${ }^{1,2}$ On behalf of the CohMSM Study Group
}

\begin{abstract}
- Additional material is published online only. To view please visit the journal online (http://dx.doi.org/10.1136/ sextrans-2018-053892).
\end{abstract}

For numbered affiliations see end of article.

\section{Correspondence to} Mr Pierre-Julien Coulaud, Aix Marseille Univ, INSERM, IRD, SESSTIM, Sciences Economiques \& Sociales de la Santé \& Traitement de I'Information Médicale, Marseille, France; pj1188@hotmail.com

Received 9 November 2018 Revised 10 June 2019 Accepted 9 July 2019
Check for updates

\section{(c) Author(s) (or their} employer(s)) 2019. No commercial re-use. See rights and permissions. Published by BMJ.

\begin{tabular}{|l|}
\hline To cite: Coulaud P-J, \\
Sagaon-Teyssier L, \\
Mimi M, et al. \\
Sex Transm Infect Epub ahead \\
of print: [please include Day \\
Month Year]. doi:10.1136/ \\
sextrans-2018-053892
\end{tabular}

\section{ABSTRACT}

Objectives Whether regular HIV testing and counselling reduce risky sexual behaviours in African men who have sex with men (MSM) is still a matter for debate. We aimed to identify behavioural trajectories based on HIV risk exposure (HRE) and factors affecting their evolution.

Methods Data were collected from 621 HIV-negative West African MSM (Mali, Cote d'Ivoire, Burkina Faso and Togo) included in a community-based cohort providing quarterly HIV testing and counselling. Sociobehavioural data were collected every 6 months. HRE was defined as reporting inconsistent condom use during receptive anal sex with male partners of unknown HIV status in the previous 6 months. Using 18-month follow-up data, group-based trajectory modelling helped identify behavioural trajectories and determine the factors associated with their evolution. HIV seroconversions $(n=67)$ were specified in each group trajectory.

Results Two distinct group trajectories were identified: medium-risk exposure MSM (ME-MSM) (61\%, 6.4\% of whom having seroconverted) and high-risk exposure MSM (HE-MSM) (39\%, 17.5\% of whom having seroconverted). A significant declining trend in the probability of reporting HRE over time $((95 \% \mathrm{CI}))$ was observed for HE-MSM (from 0.59 (0.48 to 0.70 ) at $\mathrm{M} 0$ to 0.31 (0.22 to 0.41$)$ at M18), while it remained constant for ME-MSM (0.034 (0.0 to 0.079)). This can be explained by a progressive use of risk reduction strategies (less receptive anal sex, better knowledge of their partners' status and increasing condom use). Being younger, living in Burkina Faso, self-considering both a man and a woman and reporting a higher level of depression were all associated with HE membership. Among HE-MSM, HRE was higher in those practising transactional or group sex and those experiencing psychological harassment.

Conclusions Quarterly HIV testing and counselling seem to reduce risky sexual behaviours in HIV-negative MSM at greatest risk of infection. Specific support for young MSM, focusing on identity and mental health, is needed to strengthen HIV prevention in West African MSM.

\section{INTRODUCTION}

Improving access to HIV testing and counselling for men who have sex with men (MSM) is needed to limit their engagement in risky sexual behaviours, ${ }^{1}$ and multiple innovative prevention programmes have been implemented in the last decade using different approaches such as mobile phone or internet approaches, peer-led outreach, sex venuebased outreach. ${ }^{2}$ Nevertheless, to date, these initiatives have been insufficient to reach the first target of the UNAIDS 90-90-90 objectives, given that nearly half of MSM infected with HIV worldwide are still unaware of their status. ${ }^{2}$ Individual, structural and social factors such as low risk perception, lack of MSM-friendly clinics and stigma have been previously described as barriers to accessing HIV prevention services. ${ }^{2-4}$ In response to this, the WHO recommend regularly offering HIV testing for MSM as part of a comprehensive package of prevention services that comprises counselling, behavioural interventions and the provision of preventive tools. ${ }^{1}$ Greater knowledge about sexual risk behaviours of HIV-negative MSM in terms of regular HIV testing and counselling is crucial to improve the efficiency of this new preventive approach.

Involving MSM in prevention programmes has been identified as an essential lever to increase access to HIV preventive services, especially in socially hostile environments such as sub-Saharan Africa, ${ }^{5}{ }^{6}$ where stigma and discrimination are important issues inside and outside health services. ${ }^{67}$ Previous studies highlighted the benefits of community-based research on African MSM participation and engagement in HIV services. ${ }^{3}{ }^{8-11}$ However, most only focused on assessing HIV incidence. $^{3}{ }^{8-11}$ Very few investigated HIV risk 
behaviours in a longitudinal context. Among the latter, a retrospective study among Senegalese MSM have shown an increase of condom use during anal sex (receptive or insertive) between two surveys in 2004 and 2007..$^{12}$ However, this assessment was not clearly linked to participation in HIV prevention activities. Another study demonstrated that the promotion of regular risk reduction counselling in Kenyan MSM contributed to a reduction in risky sexual behaviours. ${ }^{13}$ In-depth analyses in collaboration with MSM community-based organisations are needed to better understand the potential effect of a comprehensive preventive package on HIV risk behaviours and to inform future HIV services willing to offer such a package to MSM.

Since 2015, the CohMSM study has been implemented in West African community-based organisations, providing a quarterly preventive package including HIV testing and counselling. The objective of this analysis is twofold: first, to characterise HIV-negative MSM who have higher risk of HIV exposure on the basis of their risky sexual behaviours during follow-up, and second to study both the evolution of these behaviours during follow-up and associated factors.

\section{METHODS}

\section{Study design}

In June 2015, an ongoing prospective cohort study of MSM (CohMSM), was initiated in four West African countries: Mali (Bamako), Côte d'Ivoire (Abidjan), Burkina Faso (Ouagadougou) and Togo (Lomé). In each country, participants are recruited and followed up by a community-based organisation providing services for HIV prevention, care and support. To be eligible, MSM must be aged 18 years or older and report at least one episode of anal intercourse with another man within the 3 months prior to enrolment.

Participants are offered a quarterly preventive package including free clinical examination, screening for HIV, screening and treatment for other STIs, access to postexposure prophylaxis, individualised peer-led support, condoms and lubricants. At each follow-up visit, physicians provide pre-HIV and post-HIV test counselling, while trained peer-educators deliver specific individual counselling, including the promotion of quarterly HIV/STI testing, the use of condoms and lubricants and risk reduction strategies. Pre-exposure prophylaxis (PrEP) was not included in this package. Participants diagnosed with HIV are proposed immediate initiation of antiretroviral treatment irrespective of their WHO clinical stage and CD4 cell count.

Clinical data including results of HIV and STI testing are recorded at each follow-up visit. Participants are required to complete a standardised face-to-face questionnaire administered by a research assistant on enrolment and every 6 months thereafter to collect data on their sociodemographic and behavioural characteristics.

\section{Study population}

Of the 778 participants enrolled in the CohMSM study between June 2015 and January 2018, the 157 diagnosed with HIV at enrolment were excluded from the present analysis. Analyses were performed on data collected during the first 18 months of follow-up.

\section{Outcome}

The main outcome was constructed on the basis of the following indicators: (1) inconsistent condom use during receptive anal sex with regular and casual partners ('almost always', 'sometimes', 'never"' vs 'always') and (2) knowledge of HIV status among regular ('no, I don't know' vs 'yes, he is HIV-positive' or 'yes, he is HIV-negative') and casual sexual partners ('systematically' vs 'often', 'sometimes' or 'never'). The measure of these indicators corresponded to all sexual intercourses over the previous 6 months. Accordingly, participants were classified in two categories: (1) those declaring inconsistent condom use during receptive anal sex with male partners whose HIV status is unknown or known positive (high exposure) and (2) those reporting inconsistent condom use only during insertive anal sex with male partners of unknown HIV status (medium exposure). If they also had receptive anal sex, these practices were consistent condom protected. Those using consistent condom during insertive anal sex and those who declared that their sexual partners were HIV negative or HIV positive were also considered as a medium exposure. The same variable was constructed for all the point-times in the follow-up: M0, M6, M12 and M18.

To better describe the evolution of our main outcome over time, two secondary composite outcomes were created: (1) participants reporting receptive anal sex in the previous 6 months ('yes' vs 'no') and (2) participants reporting receptive anal sex with partners of unknown HIV status in the previous 6 months ('yes' vs 'no').

\section{Explanatory variables}

The following individual characteristics were specified as timefixed variables: city, age, marital status (married/in a relationship vs single), education (secondary school or lower vs higher than secondary school), employment status (student, employed, unemployed or manual worker) and self-perception of financial situation (comfortable/just making ends meet vs difficult/very difficult). Psychosocial variables were as follows: self-defined sexual identity (homosexual/gay vs bisexual) and gender self-identity (only a man vs both a man and a woman), level of self-esteem in the previous 6 months before baseline (measured using the Rosenberg scale, Cronbach's alpha $(\alpha)=0.96$ ), level of depression in the previous 6 months before baseline (assessed with the Patient Health Questionnaire-9, ${ }^{14} \alpha=0.84$ ) and experiencing stigma in the previous 6 months before baseline (using a score of five items adapted from a previous study, ${ }^{15} \alpha=0.68$ ).

Sexual behaviour variables in the previous 6 months were specified as time-varying as they were collected at each time-point in the follow-up: having at least one female partner, declaring threats or psychological harassment by a sexual partner, participating in group sex, reporting transactional sex (ie, 'having sex with a man to receive money, accommodation or other material benefit'), and drug use ('never' vs 'at least once').

Having at least one STI at enrolment was recorded using a syndromic approach (ie, anal and genital ulceration, discharge, condyloma, anal fistula and fissure).

\section{Statistical analysis}

Descriptive statistics of the main characteristics of participants was presented. Group-based trajectory modelling with a logistic specification was implemented to identify subgroups of participants with similar patterns of HIV risk exposure (ie, group trajectories) dispensing over time during the 18-month follow-up period (see online supplementary appendix 1 for more details about the identification of trajectories). The construction of these group trajectories was based on data collected for those participants with at least two observed time-points during the follow-up. This corresponded to 515 participants with a median follow-up duration of 18.7 months (Interquartile Range (IQR): 15.2-24.3). The remaining 106 participants (ie, those with only one time-point) were assigned to the group trajectory according to their risk of HIV exposure at baseline. This did not introduce any bias, as the 106 participants 
were not different from the other 515 in terms of their sociodemographic and behavioural characteristics (data not shown).

This model also allowed for joint estimation of the individual characteristics determining group membership as time-fixed factors and time-varying factors associated with the shape of the trajectories. An advantage of using this joint estimation process is that it yields SEs that account for the uncertainty of group assignments. ${ }^{16}$ A backward elimination procedure based on the Wald test was used to select variables in the final model.

Then, the distribution of HIV seroconversions between group trajectories was compared using the $\chi^{2}$ test to verify the pertinence of the estimated trajectories regarding the risk of HIV exposure. Evolution of our outcome and variables of interest over the follow-up time was also described. Analyses were performed using SAS software (V.9.4).

\section{RESULTS}

\section{Participants' baseline characteristics}

A total of 621 HIV-negative MSM were included in the present analysis, which 450, 400 and 270 have completed follow-up questionnaire at M6, M12 and M18, respectively (table 1). Of these, $40 \%$ were from Bamako and, respectively, 22\%, 20\% and 19\% lived in Abidjan, Ouagadougou and Lomé. Median age was 23 years (IQR: 21-27), 72\% were single, 38\% were students and $60 \%$ reported financial difficulties. Most participants self-identified as bisexual (55\%) and considered themselves to be a man only (58\%). Median scores (IQR) for self-esteem, depression and stigma were 18 (16-19), 2 (0-6) and 5 (5-7), respectively. Forty-two per cent had at least one female partner, while one in three reported transactional sex (32\%) and group sex (26\%), and experiencing psychological harassment (28\%). Only 11\% used drugs and 13\% had an STI at enrolment.

Most participants (61\%) reported receptive anal sex in the previous 6 months and half of them (47\%) had sex with partners of unknown HIV status. Among the latter, one-third (29\%) reported inconsistent condom use. None of the participants reported inconsistent condom use during receptive anal sex with HIV-positive partners.

\section{Sexual risk group trajectories}

Based on the Bayesian Information Criterion values, the fit of the estimated models decreased continuously from the two-group (900.5) to the third-group (904.0) and the fourth-group model (914.7). Accordingly, the best compromise between parsimony, fit and interpretability included two distinct HIV risk exposure groups trajectory (figure 1), which we labelled 'medium-risk exposure' MSM (ME-MSM) $(\mathrm{n}=376,61 \%)$ and 'high-risk exposure' (HE-MSM) $(n=245,39 \%)$. The average posterior probability of belonging to the HE-MSM group and ME-MSM group was, respectively, 0.88 and 0.88 , which indicates good classification quality of our model. ${ }^{17}$

The estimated probability of engaging in risky sexual behaviours over time for ME-MSM remained constant at 0.034 (95\% CI 0.0 to 0.079$)$, while it started at 0.59 (95\% CI 0.48 to 0.70 ] and significantly decreased to 0.31 (95\% CI 0.22 to 0.41 ) for HE-MSM $(\mathrm{p}<0.001)$. Baseline characteristics of HIV risk exposure groups are presented in online supplementary materials (online supplementary appendix table 1 ).

The distribution of HIV seroconversions over the first 18 months of follow-up (table 2) between the two group trajectories confirms the level of HIV risk exposure in both group trajectories and supports the validity of their construction, as the proportion of seroconverted individuals in the HE-MSM group was significantly
Table 1 Baseline characteristics of study participants, $n=621$ (West Africa, CohMSM study)

\begin{tabular}{|c|c|}
\hline & $\begin{array}{l}\mathrm{n}(\%) \text { or } \\
\text { median } \\
(\mathrm{IQR})\end{array}$ \\
\hline \multicolumn{2}{|l|}{ City } \\
\hline Bamako & $246(40)$ \\
\hline Ouagadougou & $124(20)$ \\
\hline Abidjan & $134(22)$ \\
\hline Lomé & $117(19)$ \\
\hline Age (in years) & $23(21-27)$ \\
\hline \multicolumn{2}{|l|}{ Marital status } \\
\hline Single & $450(72)$ \\
\hline Married/in a relationship & $93(15)$ \\
\hline Missing data & $78(13)$ \\
\hline \multicolumn{2}{|l|}{ Education } \\
\hline Higher than secondary school & $333(54)$ \\
\hline Secondary school or less & $210(34)$ \\
\hline Missing data & $78(12)$ \\
\hline \multicolumn{2}{|l|}{ Employment status } \\
\hline Student & $236(38)$ \\
\hline Employed & $188(30)$ \\
\hline Unemployed or manual worker & $79(13)$ \\
\hline Missing data & $118(19)$ \\
\hline \multicolumn{2}{|l|}{ Self-perception of financial situation } \\
\hline Difficult/very difficult & $371(60)$ \\
\hline Comfortable/just making ends meet & $172(28)$ \\
\hline Missing data & $78(12)$ \\
\hline \multicolumn{2}{|l|}{ Psychological data } \\
\hline \multicolumn{2}{|l|}{ Self-defined sexual identity } \\
\hline Bisexual & $340(55)$ \\
\hline Not bisexual & $281(45)$ \\
\hline \multicolumn{2}{|l|}{ Gender identity } \\
\hline Only a man & $353(58)$ \\
\hline Both man and woman & $258(42)$ \\
\hline Self esteem & $18(16-19)$ \\
\hline Depression & $2[0-6)$ \\
\hline Experiencing stigma in the previous 6 months & $5(5-7)$ \\
\hline \multicolumn{2}{|l|}{ Behavioural data } \\
\hline \multicolumn{2}{|l|}{$\begin{array}{l}\text { Having at least one female partner in the previous } \\
6 \text { months }\end{array}$} \\
\hline Yes & $259(42)$ \\
\hline No & $362(58)$ \\
\hline
\end{tabular}

Declaring threats or psychological harassment by a sexual partner in the previous 6 months

\begin{tabular}{lc} 
Yes & $161(28)$ \\
No & $449(72)$ \\
Missing data & $11(2)$ \\
Reporting transactional sex in the previous \\
6 months \\
Yes \\
No \\
Having group sex in the previous 6 months \\
Yes & $197(32)$ \\
No & $424(68)$ \\
Drug use in the previous 6 months & $159(26)$ \\
Yes & $462(74)$ \\
No & $68(11)$ \\
Missing data & $435(70)$ \\
& $118(19)$ \\
\hline
\end{tabular}




\begin{tabular}{|c|c|}
\hline & $\begin{array}{l}\mathrm{n}(\%) \text { or } \\
\text { median } \\
(\mathrm{IQR})\end{array}$ \\
\hline \multicolumn{2}{|l|}{ Clinical data } \\
\hline \multicolumn{2}{|c|}{ At least one STI at enrolment } \\
\hline Yes & $80(13)$ \\
\hline No & $540(87)$ \\
\hline Missing data & $1(0)$ \\
\hline \multicolumn{2}{|c|}{ Outcome and variables of interest } \\
\hline \multicolumn{2}{|c|}{ Reporting receptive anal sex in the previous 6 months } \\
\hline Yes & $381(61)$ \\
\hline No & $240(39)$ \\
\hline \multicolumn{2}{|c|}{$\begin{array}{l}\text { Reporting receptive anal sex with partners of unknown HIV status in } \\
\text { the previous } 6 \text { months }\end{array}$} \\
\hline Yes & $294(47)$ \\
\hline No & $327(53)$ \\
\hline \multicolumn{2}{|c|}{$\begin{array}{l}\text { Inconsistent condom use during receptive anal sex in the previous } 6 \\
\text { months with sexual male partner of unknown HIV serostatus }\end{array}$} \\
\hline Yes & $178(29)$ \\
\hline No & $443(71)$ \\
\hline
\end{tabular}

higher than that in the ME-MSM group $(\mathrm{p}<0.001)$ (respectively, $17.5 \%(43 / 245)$ and $6.4 \%(24 / 376))$. The absence of any significant difference in seroconversions between these two groups for the period M12-M18 ( $=0.583)$ reflects the decrease in risk exposure among HE-MSM.

\section{HIV risk exposure evolution over time}

All outcomes related to HIV risk exposure tend to decline over time in the HE-MSM group. Proportions of participants having receptive anal sex and this with adding the knowledge of partners HIV status declined between M0 and M18, respectively, of $25 \%$ and $27 \%$. The most important decrease $(57 \%)$ is due to the increasing of consistency condom use over time, ranged from $72 \%$ at M0 to $31 \%$ at M18. In contrast, similar proportions over time were found in the ME-MSM group, as illustrated on the shape of the trajectory. Online supplementary (online supplementary appendix table 2) presents the evolution of HIV risk exposure and other outcomes in each group described above.

\section{Membership to sexual risk group trajectories and changes over time}

Factors associated with group trajectory membership indicate that younger age (Odds Ratio (OR) (95\% Confidence Interval): 0.91 per 1 year increase (0.86 to 0.96$)$ ), considering oneself to be both a man and a woman (OR: 5.79 (3.26 to 10.29), compared with
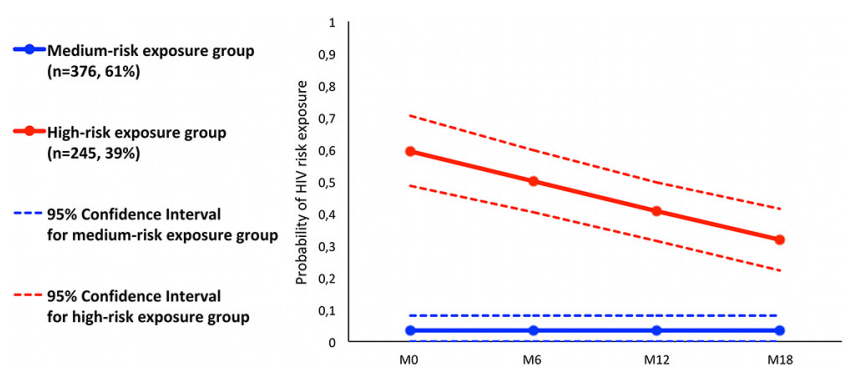

Figure 1 Trajectories of HIV risk exposure among the $621 \mathrm{HIV}$ negative participants (CohMSM study) (see online supplementary file). considering oneself to be only a man) and reporting a high level of depression (OR: 1.06 per 1-point increase (1.00 to 1.13)) were all associated with belonging to the HE-MSM group trajectory (table 3). Conversely, participants living in Ouagadougou (OR: 0.33 (0.13 to 0.85$)$, compared with participants living in Lomé) were less likely to belong to the HE-MSM group trajectory.

Table 3 also shows that the pattern of group trajectories was shaped by behavioural characteristics. Among HE-MSM participants, HIV risk exposure was more probable when they reported transactional sex $(\beta: 0.58, p=0.002)$, when they had experienced psychological harassment $(\beta: 0.67, p=0.008)$ and when they had participated in group sex $(\beta: 0.65, \mathrm{p}=0.016)$. It was less probable when they had a female partner $(\beta$ : $-0.49, \mathrm{p}=0.007)$. However, no significant factor was associated with the dynamic of the ME-MSM group trajectory.

\section{DISCUSSION}

All the West African MSM followed in this community-based cohort were, by definition, at risk of HIV infection. Most participants engaged in this cohort were young single MSM, students with low incomes, expressing multiple identities and reporting HIV risk behaviours. However, a large proportion of them (almost $40 \%$ of 621 participants) was at greater risk (ie, HE-MSM), as they engaged in more risky sexual behaviours and were more likely to seroconvert during follow-up. They were younger, considered themselves to be both a man and a woman and reported a higher number of depressive symptoms. This result suggests that the community-based approach through the network of MSM peer-educators appears to be an appropriate strategy to better target those who are the most exposed to HIV.

Our findings also show that MSM reporting higher HIV risk of exposure decreased their risky sexual behaviours over the first 18 months of follow-up, suggesting a potential positive effect of the preventive package on those who need it most. This decrease seems to be confirmed by the non-significant difference in terms of HIV seroconversion compared with the ME-MSM group at the end of follow-up. Furthermore, this reduction may be explained by a progressive use of combination of preventive strategies. As the period of follow-up increase, some participants appear to reduce practising receptive anal sex, while other know more frequently the HIV status of their sexual partners or increase the use of condoms. It is also important to note that using condoms more consistently seem to have the most significant effect on risky sexual behaviours compared with the two other strategies. Indeed, the promotion of condom use do not refer to the same nature of counselling than investigating the HIV status of the partners or changing the sexual position which depend on the personal and relational aspects with the partner. These findings show that MSM are in need of a comprehensive counselling including a package of risk-reduction strategies (ie, serosorting, withdrawal and condom use) to prevent themselves more effectively against HIV infection.

Our findings highlight that the evolution of HIV risk exposure in HE-MSM was influenced by several sociobehavioural determinants. Declaring threats or psychological harassment by one's sex partner was associated with increased risk exposure to HIV. Experiencing verbal harassment was closely associated with both a high level of internalised stigma and mental health disorders, which may result in inconsistent condom use or limit access to HIV services. ${ }^{18-20}$ Sekoni et $a l^{21}$ also showed that aggression was experienced more by MSM who identified themselves as homosexual or transgender, demonstrating the link between violence and living their sexuality more openly. These results suggest that 
Table 2 HIV-seroconversion according to group trajectory (CohMSM study)

\begin{tabular}{|c|c|c|c|c|}
\hline & HIV seroconversion & $\begin{array}{l}\text { Medium-risk exposure } \\
(\mathrm{n}=376,61 \%)\end{array}$ & $\begin{array}{l}\text { High-risk exposure } \\
(n=245,39 \%)\end{array}$ & \\
\hline & $\mathrm{N}(\%)$ & $n(\%)$ & $\mathrm{n}(\%)$ & P value* \\
\hline \multicolumn{5}{|c|}{ Total follow-up time } \\
\hline \multicolumn{5}{|l|}{ Intervals } \\
\hline M0-M6 & $28(42)$ & $12(3.2)$ & $16(6.5)$ & 0.050 \\
\hline
\end{tabular}

${ }^{*} \mathrm{P}$ value calculated using $\chi^{2}$ test.

specific services for violence on MSM should be integrated into the HIV care package. Other factors significantly associated with increased high-risk sexual behaviours were participating in transactional sex and group sex. These results are consistent with previous studies conducted in African settings. ${ }^{10} 22$ Conversely, having a female sexual partner was associated with a lower probability of reporting high-risk sexual behaviours. This could be due to these MSM having less sexual intercourses or male partners than those who only reported sex with men, as previously described in a study conducted in Nigeria. ${ }^{23}$

This study has several limitations. First, participants were recruited through the network of community-based organisations, and as such, may not represent the general MSM community in the four study countries. More specifically, given that these organisations are the major actors of HIV prevention for MSM in these countries, MSM who were not included in this study may have less access to preventive activities and risk-reduction messages. Nevertheless, it is also more probable that those who were not included in this cohort are more likely to report less frequent sexual intercourse, to have more female partners than male partners or to be more insertive than receptive during anal sex. In that case, they could be less exposed to HIV than in our study population.
Second, our findings are based on observational data that limits the scientific scope of this study. The CohMSM study was not designed with a control group of MSM who did not receive the preventive follow-up. Accordingly, we were not able to evaluate the impact of this intervention (quarterly HIV testing and counselling) on HIV risk behaviours, especially the influence of being followed in community-based organisations. A randomised control trial to compare a community-based intervention with data collected in another context, for example, in MSM who can have access to other HIV services, could be an appropriate methodology to assess the effectiveness of this intervention.

In conclusion, the comprehensive preventive package including quarterly HIV testing and counselling seemed to partially reduce risky sexual behaviour in HIV-negative participants, especially for those most at risk of HIV. In light of the high number of HIV seroconversions during follow-up, this encouraging positive effect is nonetheless insufficient. PrEP needs to be introduced into this preventive package to more efficient prevention of new HIV infections in the West African MSM population.

Table 3 Baseline determinants affecting the probability of group trajectory membership and factors associated with group trajectory dynamics (CohMSM study)

\begin{tabular}{|c|c|c|c|c|}
\hline & \multicolumn{3}{|l|}{ Group trajectories } & \multirow[b]{3}{*}{$P$ value } \\
\hline & $\left(n=610^{*}\right)$ & & & \\
\hline & $\begin{array}{l}\text { Medium-risk exposure } \\
(\mathrm{n}=376,61 \%)\end{array}$ & \multicolumn{2}{|l|}{$\begin{array}{l}\text { High-risk exposure } \\
(\mathrm{n}=245,39 \%)\end{array}$} & \\
\hline $\begin{array}{l}\text { Baseline factors affecting the probability of group } \\
\text { trajectory membership }\end{array}$ & Ref. & $\mathrm{OR}$ & $95 \% \mathrm{Cl}$ & \\
\hline Age (per 1 year increase) & & 0.91 & 0.86 to 0.96 & 0.001 \\
\hline \multicolumn{5}{|l|}{ City (ref. Lomé) } \\
\hline Bamako & & 0.49 & 0.24 to 1.00 & 0.050 \\
\hline Abidjan & & 0.91 & 0.36 to 2.33 & 0.848 \\
\hline Ouagadougou & & 0.33 & 0.13 to 0.85 & 0.022 \\
\hline $\begin{array}{l}\text { Considered themselves to be both a man and a woman } \\
\text { (ref. only a man) }\end{array}$ & & 5.79 & 3.26 to 10.29 & $<0.0001$ \\
\hline Depression (per 1-point increase) & & 1.06 & 1.00 to 1.13 & 0.049 \\
\hline Time-varying covariatest & Coeff. (SE) & $P$ value & Coeff. (SE) & $P$ value \\
\hline Reporting transactional sex (for money) & $-2.63(4.58)$ & 0.566 & $0.58(0.19)$ & 0.002 \\
\hline $\begin{array}{l}\text { Declaring threats or psychological harassment by a sexual } \\
\text { partner }\end{array}$ & $1.29(1.44)$ & 0.371 & $0.67(0.25)$ & 0.008 \\
\hline Having group sex & $0.66(1.19)$ & 0.581 & $0.65(0.27)$ & 0.016 \\
\hline Having at least one female sexual partner & $-3.64(5.83)$ & 0.531 & $-0.49(0.18)$ & 0.007 \\
\hline
\end{tabular}

*Eleven missing data.

†In the previous 6 months.

$\mathrm{Cl}$, Confidence Interval; OR, Odds Ratio; SE, Standard Error. 


\section{Key messages}

- High level of HIV risk exposure was found in men who have sex with men (MSM) who were followed up in a comprehensive preventive package.

- Even in absence of pre-exposure prophylaxis, a comprehensive preventive package can lead to a reduction of risky sexual behaviours among the most at risk HIV-negative MSM.

- Specific support for young MSM, focusing on identity and mental health, is needed to strengthen HIV prevention in West Africa.

- Further research is needed to assess the effectiveness of a comprehensive preventive package on risky sexual behaviours among MSM.

\section{Author affiliations}

${ }^{1}$ Aix Marseille Univ, INSERM, IRD, SESSTIM, Sciences Economiques \& Sociales de la Santé \& Traitement de l'Information Médicale, Marseille, France

${ }^{2}$ ORS PACA, Observatoire régional de la santé Provence-Alpes-Côte d'Azur, Marseille, France

${ }^{3}$ ARCAD-SIDA, Bamako, Mali

${ }^{4}$ Espace Confiance, Abidjan, Côte d'Ivoire

${ }^{5}$ Association African Solidarité, Ouagadougou, Burkina Faso

${ }^{6}$ Centre MURAZ, Bobo-Dioulasso, Burkina Faso

${ }^{7}$ Association Africaine Solidarité, Ouagadougou, Burkina Faso

${ }^{8}$ Espoir Vie Togo, Lomé, Togo

${ }^{9}$ Community-based Research Laboratory, Coalition PLUS, Pantin, France

${ }^{10}$ IRD, INSERM, Univ Montpellier, TransVIHMI, Montpellier, France

\section{Handling editor Henry John Christiaan de Vries}

Acknowledgements We sincerely thank the MSM participants and the staff of the community-based organisations (ARCAD-SIDA, Espace Confiance, Association African Solidarité, Espoir Vie Togo) who participated in the CohMSM study. Our thanks also to Jude Sweeney for the English revision.

\section{Collaborators}

The CohMSM Study Group: Clotilde Couders, Bruno Granouillac, Suzanne Izard, Christian Laurent, Laura March, Martine Peeters, Laetitia Serrano (IRD, INSERM, Univ Montpellier, TransVIHMI, Montpellier, France); Cyril Berenger, Michel Bourrelly, Pierre-Julien Coulaud, Gwenaëlle Maradan, Bakri M'madi Mrenda, Marion Mora, Enzo Parisi, Luis Sagaon-Teyssier, Bruno Spire (INSERM, IRD, Univ Aix-Marseille, SESSTIM, Marseille, France); Adeline Bernier, Paméla Palvadeau, Daniela Rojas Castro (Coalition Internationale Sida, Pantin, France); Drissa Camara, Oumar Cisse, Alou Coulibaly, Bintou Dembele Keita, Fodié Diallo, Mahamadou Diarra, Mady Gadjigo, Abdoul Aziz Keita, Kader Maiga, Aly Ouologuem, Fodé TRAORE (ARCADSIDA, Bamako, Mali): Niamkey Thomas AKA, Camille Anoma, Stéphane-Alain BABO YORO, Noufo Hamed COULIBALY, Rachelle KOTCHI, Patrick KOUABENAN, Malan Jean-Baptiste KOUAME, Kpassou Julien LOKROU, Frédéric Dibi N'GUESSAN (Espace Confiance, Abidjan, Côte d'Ivoire); Xavier ANGLARET, Jean-Marie MASUMBUKO, Maxime OGA (PACCl, Abidjan, Côte d'Ivoire); Christian COULIBALY, Ter Tiero Elias DAH, Ousseni ILBOUDO, Joseph OUEDRAOGO, Mamadou OUEDRAOGO, Elisabeth THIO, Juste Rodrigue TOURE, Abdoulazziz TRAORE, Issa TRAORE (Association African Solidarité, Ouagadougou, Burkina Faso); Fiffou YOUGBARE (Centre National de Transfusion Sanguine, Ouagadougou, Burkina Faso); Nicolas MEDA (Centre de Recherche Internationale pour la Santé, Ouagadougou, Burkina Faso): Kouakou Kokouvi Selom AGBOMADJI, Richard Mawuényégan Kouamivi AGBOYIBOR, Messan ATTIOGBE, Aléda Mawuli BADJASSIM, Agbégnigan Lorette EKON, Anouwarsadat KOKOUBA, Ephrem MENSAH, Diimiln Joseph Strauss TABLISSI, Kossi Jeff YAKA (Espoir Vie Togo, Lomé, Togo); Claver Anoumou Yaotsè DAGNRA (Laboratoire BIOLIM, Univ Lomé, Lomé, Togo).

Contributors PJC implemented this work under supervision of LST and BS. AAK, SABY, ETTD, ChC, EM and SA performed data collection under supervision of $\mathrm{CIC}$, MaM and GM. PJC, MoM and LST led the analysis. The manuscript was written by PJC, with input from LST, BS and CL. BDK, CA, ETTD, EM, BS, MB and CL provided ongoing support throughout the cohort study. All authors approved the final manuscript.
Funding This study was funded by the ANRS (France Recherche Nord \& Sud Sida-hiv Hépatites; ANRS 12324) and Expertise France (Initiative 5\%). PJC was the recipient of doctoral fellowships from ANRS (B7-ANRS 12324) and Sidaction (17-2FJC-11561)

Competing interests None declared.

Patient consent for publication Parental/Guardian consent obtained.

Provenance and peer review Not commissioned; externally peer reviewed.

Data availability statement No data are available.

\section{REFERENCES}

1 World Health Organization. Consolidated guidelines on HIV prevention, diagnosis, treatment and care for key populations - 2016 update. World Health Organization, 2016: 155.

2 Campbell CK, Lippman SA, Moss N, et al. Strategies to increase HIV testing among MSM: a synthesis of the literature. AIDS Behav 2018;22:2387-412.

3 Dramé FM, Crawford EE, Diouf D, et al. A pilot cohort study to assess the feasibility of HIV prevention science research among men who have sex with men in Dakar, Senegal. J Int AIDS Soc 2013;16:18753.

4 Sullivan PS, Carballo-Diéguez A, Coates T, et al. Successes and challenges of HIV prevention in men who have sex with men. The Lancet 2012;380:388-99.

5 Trapence G, Collins C, Avrett S, et al. From personal survival to public health: community leadership by men who have sex with men in the response to HIV. The Lancet 2012;380:400-10.

6 Beyrer C, Sullivan PS, Sanchez J, et al. A call to action for comprehensive HIV services for men who have sex with men. The Lancet 2012;380:424-38.

7 Abara WE, Garba I. Hiv epidemic and human rights among men who have sex with men in sub-Saharan Africa: implications for HIV prevention, care, and surveillance. Glob Public Health 2017;12:469-82.

8 Holland CE, Papworth E, Billong SC, et al. Access to HIV services at NonGovernmental and community-based organizations among men who have sex with men (MSM) in Cameroon: an integrated biological and behavioral surveillance analysis. PLoS One 2015;10:e0122881.

9 Couderc C, Dembélé Keita B, Anoma C, et al. Is PreP needed for MSM in West Africa? HIV incidence in a prospective multicountry cohort. JAIDS 2017;75:e80-2.

10 Sanders EJ, Okuku HS, Smith AD, et al. High HIV-1 incidence, correlates of HIV-1 acquisition, and high viral loads following seroconversion among MSM. AIDS 2013;27:437-46.

11 Price MA, Rida W, Mwangome M, et al. Identifying at-risk populations in Kenya and South Africa. JAIDS 2012;59:185-93.

12 Wade AS, Larmarange J, Diop AK, et al. Reduction in risk-taking behaviors among MSM in Senegal between 2004 and 2007 and prevalence of HIV and other STIs. ELIHOS project, ANRS 12139. AIDS Care 2010:22:409-14

13 Möller LM, Stolte IG, Geskus RB, et al. Changes in sexual risk behavior among MSM participating in a research cohort in coastal Kenya. AIDS 2015;29:S211-S219.

14 Kroenke K, Spitzer RL, Williams JB. The PHQ-9: validity of a brief depression severity measure. J Gen Intern Med 2001;16:606-13.

$15 \mathrm{Ha} \mathrm{H}$, Risser JMH, Ross MW, et al. Homosexuality-Related stigma and sexual risk behaviors among men who have sex with men in Hanoi, Vietnam. Arch Sex Behav 2015;44:349-56.

16 Nagin D. Group-based modeling of development [Internet]. Harvard University Press, 2005: 201.

17 Jones BL, Nagin DS. Advances in group-based trajectory modeling and an SAS procedure for estimating them. Sociol Methods Res 2007;35:542-71.

$18 \mathrm{Kim} \mathrm{H-Y,} \mathrm{Grosso} \mathrm{A,} \mathrm{Ky-Zerbo} \mathrm{0,} \mathrm{et} \mathrm{al.} \mathrm{Stigma} \mathrm{as} \mathrm{a} \mathrm{barrier} \mathrm{to} \mathrm{health} \mathrm{care} \mathrm{utilization}$ among female sex workers and men who have sex with men in Burkina Faso. Ann Epidemiol 2018;28:13-19.

19 Anderson AM, Ross MW, Nyoni JE, et al. High prevalence of stigma-related abuse among a sample of men who have sex with men in Tanzania: implications for HIV prevention. AIDS Care 2015;27:63-70.

20 Baral S, Trapence G, Motimedi F, et al. Hiv prevalence, risks for HIV infection, and human rights among men who have sex with men (MSM) in Malawi, Namibia, and Botswana. PLoS One 2009;4:e4997.

21 Sekoni AO, Ayoola 00, Somefun EO. Experiences of social oppression among men who have sex with men in a cosmopolitan City in Nigeria. HIV AIDS (AuckI) [Internet] 2015:7:21-7.

22 Crowell TA, Keshinro B, Baral SD, et al. Stigma, access to healthcare, and HIV risks among men who sell sex to men in Nigeria. J Int AIDS Soc 2017;20:21489

23 Sheehy M, Tun W, Vu L, et al. High levels of bisexual behavior among men having sex with men (MSM) in Nigeria. AIDS Care 2014;26:116-22. 